http://dx.doi.org/10.21707/gs.v11.n02a013

\title{
Avaliação do desempenho do Índice de Sustentabilidade Pelo DashbOARD SustainabiLITY Nas Bacias Hidrográficas dos RiOS Jaguaribe, Cabelo e Cuiá na cidade de João Pessoa (PB)
}

\author{
André Luiz Queiroga Reis ${ }^{1 *}$, Eduardo Rodrigues Viana de Lima², Maristela Oliveira de Andrade ${ }^{3}$, \\ Christianne Maria Moura Reis ${ }^{2}$ \\ ${ }^{1}$ Doutorado no Programa de Pós-graduação em Desenvolvimento e Meio Ambiente da Universidade Federal da Paraíba; Técnico do Laboratório de \\ Saneamento, Centro de Tecnologia, Universidade Federal da Paraíba \\ ${ }^{2}$ Docente do Departamento de Geociências, Centro de Ciências Exatas e da Natureza, Universidade Federal da Paraíba \\ ${ }^{3}$ Docente do Programa de Pós-graduação em Desenvolvimento e Meio Ambiente da Universidade Federal da Paraíba \\ *Autor para correspondência: andre_queiroga@yahoo.com.br
}

Recebido em 09 de março de 2016. Aceito em 14 de novembro de 2016. Publicado em 30 de junho de 2017.

Resumo - Na atualidade existe a necessidade do desenvolvimento e aplicação de técnicas de monitoramento ambiental, que apresentem e forneçam dados confiáveis, práticos e de fácil obtenção às principais esferas do poder público e população inserida nos lacustres das cidades de médio porte, como é o caso de João Pessoa, Estado da Paraíba. Uma dessas técnicas é a aplicação de Índices de Sustentabilidade, que aglutinam aspectos qualitativos e quantitativos das dimensões social, ambiental, econômica e institucional que auxiliam e estruturam o planejamento e a gestão ambiental urbana de um município, avaliando criticamente a eficácia da metodologia de gerenciamento urbano, relacionando a possiblidade de propor adaptações às intervenções urbanas. As relações entre os meios bióticos e abióticos fazem parte de um sensível equilíbrio, motivo pelo qual as alterações que interferem nessas relações presentes no ambiente urbano podem alterar a sua qualidade. Assim, desenvolver um índice que melhor represente a tendência de sustentabilidade ambiental, fornecendo informações de advertência à sociedade e ao poder público e consequentemente, propor ações de conservação e harmonização entre o ambiente urbano e os serviços ecossistêmicos fornecidos pelos rios e áreas verdes no município de João Pessoa. A metodologia utilizada neste trabalho é focada na avaliação do desempenho das quatro dimensões da sustentabilidade no entorno dos rios Cuiá, Jaguaribe, Cabelo. Conclui - se que neste trabalho são reveladas as vulnerabilidades e potencialidades de um socioecossistema urbano em descompasso com os planos e projetos de desenvolvimento das cidades em relação à harmonia com os ambientes naturais.

Palavras-chave: Ecossistemas Urbanos; Indicadores; Harmonização; Sustentabilidade.

Evaluation of PERformance of Sustainability Index by DAShboARD Sustainability In the Jaguaribe, Cabelo and Cuí́ rivers hydrographic basins in the City of João Pessoa (PB)

Abstract - Nowadays there is a need for the development and implementation of environmental monitoring techniques that present and provide reliable, practical and easy to obtain information to the main spheres of government and society inserted in medium-sized cities close to lakes, as the city of João Pessoa. One of those techniques is the Sustainability Indexes application, which puts together qualitative and quantitative aspects of social, environmental, economic and institutional dimensions that aids and give the structures for the county planning of urban and environmental management, critically evaluating the effectiveness of urban management methodology, relating the possibility of proposing adaptations tourban interventions. The relations between the biotic and abiotic means are part of a sensitive balance, which is why the changes that interfere in these relations present in the urban environment can change their quality. So, developing an 
index that best represents the environmental sustainability trend, providing warning information to society and to the government, and consequently, proposing conservation and harmonization of actions between the urban environment and the ecosystem services provided by rivers and green areas in the João Pessoa city. The methodology used in this study focused on the performance evaluation of the four dimensions of sustainability in rivers Cuiá, Jaguaribe, Cabelo. It concludes that this work reveals the vulnerabilities and the potentialities of an urban socio-ecosystemin disharmony with the city plans and development projects in relation to the natural environment harmony.

KEYWORDS: HARMONIZATION; INDICATORS; SUSTAINABILITY; URBAN ECOSYSTEMS.

Evaluación del desempeño del Índice de Sostenibilidadpor el Dashboard Sustainability en las Cuencas Hidrográficas de los ríos Jaguaribe, Cabello y Cuia en la ciudad de João Pessoa (PB)

REsumen - En la actualidad existe la necesidad del desarrollo y aplicación de técnicas de monitoreo ambiental, que presenten y suministren datos confiables, prácticos y de fácil obtención paralas principales esferas del poder público y población inserta en áreaslacustres de las ciudades de mediano porte, como es el caso de João Pessoa, Estado de Paraíba. Una de esas técnicas es la aplicación de Índices de Sostenibilidad, que aglutinan aspectos cualitativos y cuantitativos de las dimensiones social, ambiental, económica e institucional que auxilian y estructuran el planeamiento y la gestión ambiental urbana de un municipio, evaluando críticamente la eficacia de la metodología de gestión urbana, relacionando la posibilidad de proponer adaptaciones a las intervenciones urbanas. Las relaciones entre los medios bióticos y abióticos forman parte de un sensible equilibrio, motivo por el cuallas alteraciones que interfieren en esas relaciones presentes en el ambiente urbano pueden alterar su calidad. Así, desarrollar un índice que mejor represente la tendencia de sostenibilidadambiental, proporcionando informaciones de advertencia a la sociedad y al poder público y consecuentemente, proponer acciones de conservación y armonización entre el ambiente urbano y los servicios ecosistémicos proporcionados por los ríos y áreas verdes en el municipio de João Pessoa. La metodología utilizada en este trabajo se enfoca en la evaluación del desempeño de las cuatro dimensiones de la sostenibilidad en el entorno de los ríosCuiá, Jaguaribe, Cabelo. Se concluye que en este trabajo se revelan las vulnerabilidades y potencialidades de un socioecosistema urbano en descompás con los planes y proyectos de desarrollo de las ciudades en relación a la armonía con los ambientes naturales.

Palabras-clave: Ecosistemas Urbanos; Indicadores; Armonización; Sostenibilidad.

\section{INTRODUÇÃO}

Reis et al. (2005) descrevem que um modelo de desenvolvimento sustentável deve ser capaz não só de contribuir para a superação dos atuais problemas, mas também de garantir a própria vida, por meio da proteção e manutenção dos sistemas naturais. Para tanto é possível fazer uso de métodos de avaliação e planejamento que caracterizem o ecossistema possibilitando a criação de uma estratégia integrada na gestão e conservação destes, culminando na identificação de indicadores e índices de desenvolvimento sustentável local, de forma dinâmica.

Fornecendo a imagem real da situação de sustentabilidade e possibilitando agregar e quantificar informações, tornando - as mais significativas, de fácil entendimento e financeiramente viáveis. Contudo, para que tais métodos de avaliação sejam eficazmente utilizados faz-se necessário uma revisão de pressupostos éticos dos atuais modelos de organização econômica e social. Buarque (2008, p. 62) diz:

[...] tanto a natureza quanto a sociedade (incluindo o sistema econômico) constituem sistemas complexos em equilíbrio dinâmico que combinam uma tendência a desorganização e uma capacidade de auto-organização e auto-regeneração [...]. 
Segundo Van Bellen (2006), uma das maneiras que viabiliza a sustentabilidade é o desenvolvimento e a aplicação de sistemas de indicadores ou ferramentas de avaliação que procuram mensurar a sustentabilidade.

O desenvolvimento dessa ferramenta faz uso de instrumentos técnico-científicos na construção de respostas sustentáveis que reduzam o conflito entre sociedade e meio ambiente possibilitando que se quantifique a sustentabilidade.

Isso somente será possível quando o poder público identificar, esclarecer e apresentar à sociedade os processos não sustentáveis que podem ser monitorados, avaliados e, em função dessa avaliação, os processos que podem ser mantidos, revertidos, agravados ou sanados, dependendo apenas das ações e medidas corretivas e preventivas tomadas pelo gestor público e pela população em geral, utilizando decisões políticas baseadas em informações reais, concretas e confiáveis.

Entretanto, a complexidade do conceito de desenvolvimento sustentável e suas dimensões multifacetadas, têm dificultado a utilização adequada dessa ferramenta, tendo em vista a variedade de tipos de abordagens utilizadas para avaliar o grau de sustentabilidade, em função do campo ideológico-ambiental ou da dimensão em que cada membro participante se coloca dentro das perspectivas econômica, social, ambiental, geográfica e cultural.

De acordo com Veiga e Zatzet al. (2008), o crescimento econômico sempre se deu em detrimento da conservação da natureza, uma vez que os indicadores do desenvolvimento sustentável têm demonstrado que a produção e o consumo das populações que mais enriqueceram vêm causando uma elevada pressão sobre a biosfera.

Sendo assim, uma forma utilizada para quantificar a sustentabilidade através de um acompanhamento simultâneo e dinâmico das características e variáveis de uma determinada área (bairro, bacia hidrográfica, município, região, Estado, país, etc.) é a criação de um Índice de Sustentabilidade, que utiliza a avaliação agrupada dos indicadores característicos da área como fonte de dados primários.

Para a OECD (1993), o indicador deve ser considerado um parâmetro que indique informações sobre o estado de um fenômeno de significativa relevância.

Para o IBGE (2008, p.9):

\begin{abstract}
Os indicadores são ferramentas constituídas por uma ou mais variáveis que, associadas através de diversas formas, revelam significados mais amplos sobre os fenômenos a que se referem; também são essenciais para guiar a ação e subsidiar o acompanhamento e a avaliação do progresso alcançado rumo ao desenvolvimento sustentado, sendo este, um processo em construção, a formulação de indicadores também é um trabalho em aberto.
\end{abstract}

Para Van Bellen (2006, p. 42), o objetivo principal do indicador é: "Agregar e quantificar informações de modo que sua significância seja aparente. Eles simplificam as informações sobre fenômenos complexos tentando melhorar com isso o processo de comunicação."

Mas de acordo com Beltrame (1994), é necessário eleger indicadores do meio físico ou abiótico para fins conservacionistas que indiquem as potencialidades de proteção ou degradação dos recursos naturais. Esses parâmetros foram escolhidos por refletirem as características intrínsecas de uma bacia hidrográfica no que diz respeito aos aspectos ambientais.

Portanto, o mecanismo de operação do uso de indicadores e índices é sequencial. Inicialmente é identificada a escala e o local de aplicação do planejamento para atingir a sustentabilidade, os dados primários são coletados, esses dados são analisados e comparados a uma relação de indicadores relevantes para a área de acordo com as 
dimensões da sustentabilidade e o tipo de sistema de monitoramento, o resultado quantitativo dessa comparação gera indicadores das condições do sistema separadamente.

De acordo com Van Bellen (2006), existem diversas ferramentas que monitoram o grau ou a tendência de sustentabilidade de um sistema, cada uma com vantagens e desvantagens e características diferenciadas pelo escopo, tipologia dos dados, esfera de atuação, nível de agregação, participação, complexidade, apresentação, abertura e potencial educativo.

As três metodologias reconhecidas internacionalmente são: Pegada ecológica (Ecological Footprint Method), Painel de Sustentabilidade (Dashboard of Sustainability) e o Barômetro de Sustentabilidade (Barometerof Sustainability).

O Dashboard of Sustainability (Figura 1) é um índice que representa a sustentabilidade de um sistema englobando a média de vários indicadores com pesos iguais, catalogados em quatro categorias de performance: econômica, social, ambiental e institucional. É apresentado através de uma escala de cores que varia do vermelhoescuro (resultado crítico), passando pelo amarelo (médio) até chegar ao verde-escuro (resultado positivo) e que sua representação gráfica pode ser um painel ou um gráfico de farol.

Figura1 - Apresentação de dados pelo painel de sustentabilidade

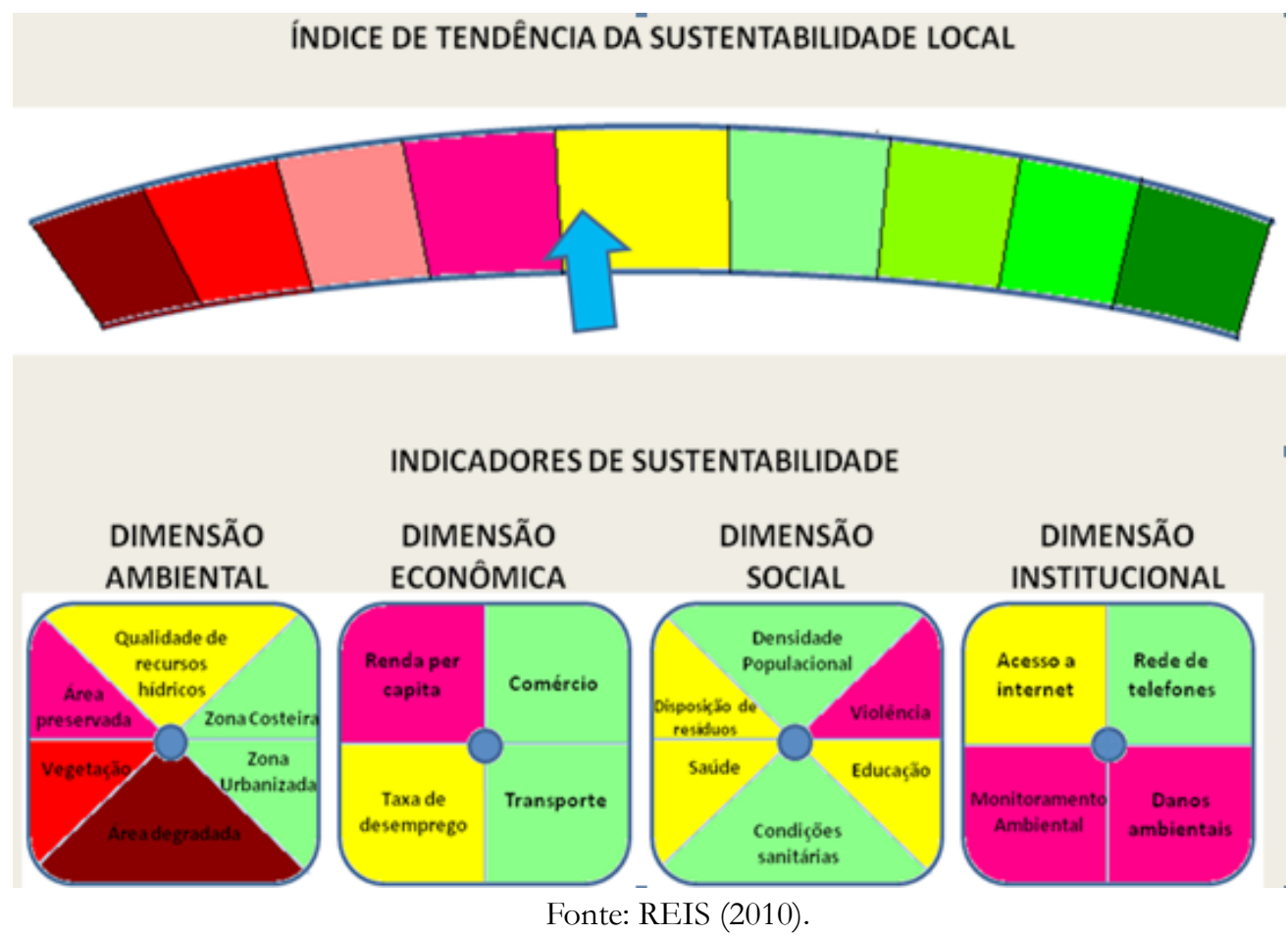

Ao representar o baixo desempenho de indicadores locais (como indicadores sociais em uma bacia hidrográfica, por exemplo) é possível corrigi-los ou melhorá-los mais rápida e eficazmente, desde que as ações tomadas atinjam a causa dos problemas. Ao reproduzir em diversos territórios da esfera local a metodologia de índices pelo Painel da Sustentabilidade, que apresentam o desempenho dos indicadores e consequentemente propõe ações de melhoria, será possível influenciar fatores da esfera regional, a reprodução dos resultados nesta esfera, proporcionará modificações nas condições da área investigada.

Mas vale salientar que é necessário um profundo compromisso ético do poder público para subsidiar programas de assistência emergencial, como moradia e acesso a serviços públicos de qualidade que garantam dignidade a população. 
Programas que fomentem e desenvolvam oportunidades de qualificação e oferta de emprego a população, bem como haja punição de crimes ambientais, proteção de áreas e recursos naturais estratégicos e recuperação de áreas degradadas.

A característica mais importante desta ferramenta é a de identificar clara e rapidamente o que precisa ser solucionado, pois se as ações forem direcionadas para resolver os verdadeiros problemas e suas reais causas, quem possui menor poder aquisitivo não irá necessitar degradar o meio ambiente, pois será papel do Estado fomentar e complementar as suas necessidades e ainda será papel do gestor público regular a oferta dos serviços públicos equitativamente a todas as classes sociais. Mas cabe ao Poder Público executar ações de efeito em longo prazo e a Sociedade Civil monitorar e fiscalizar a implementação de tais ações.

O uso da metodologia de índices pelo Painel de Sustentabilidade pode reduzir as distorções entre as escalas territoriais, pois utiliza a prerrogativa de reunir indicadores de baixa agregação e considerar as conexões com as demais escalas, transformando a área de abrangência em que foi aplicada. A metodologia é um exemplo a ser reproduzido em outras dimensões.

Este trabalho faz uso do Painel da Sustentabilidade aplicado em três bacias hidrográficas urbanas do município de João Pessoa por considerar as quatro dimensões da sustentabilidade e entender que o método de apresentação dos dados é mais simples se comparado com as duas outras metodologias (Benetti, 2006; VanBellen, 2006).

É no uso de um sistema de Índices e Indicadores que o verdadeiro ciclo DS ocorre, pois desta forma é possível visualizar o objetivo final (a sustentabilidade integrada), fazer uso de informações em escala espacial e temporal adequada (indicadores), monitorar a tendência de sustentabilidade das dimensões de forma integral (índices) e assim fornecer aos tomadores de decisão o subsidio técnico - científico que fomente a criação de políticas públicas e ações corretivas que suprimam as não conformidades no cerne das suas causas e não nos seus efeitos.

Entretanto alguns cuidados precisam ser levados em consideração na formulação dos indicadores. Um deles é a agregação de dados na formulação do indicador ou do índice.Agregar muitos dados em um indicador muitas vezes é necessário para elevar o grau de conhecimento a respeito dos problemas ou não conformidades das dimensões analisadas, contudo também devem fazer parte do método de mensuração da sustentabilidade, dados de indicadores desagregados, para que possibilitem ações específicas, em áreas específicas do escopo do sistema.

Isso quer dizer que quanto mais agregado ou agrupado o indicador, mais distante ele estará dos reais problemas do sistema analisado e consequentemente ocorrerão maiores dificuldades na articulação das medidas e estratégias a situações específicas.

A classificação dos indicadores segue o método de Painel da Sustentabilidade, bastante estudado por Van Bellen (2006), que divide a sustentabilidade em indicadores de quatro dimensões clássicas, seguindo a orientação da Comissão de Desenvolvimento Sustentável das Nações Unidas. São elas:

- DIMENSÃO SOCIAL - Indicadores formulados a partir de condições de equidade social, como saúde, condições sanitárias, segurança, educação, moradia, etc.

- DIMENSÃO ECONÔMICA - Indicadores caracterizados pelo desempenho financeiro local, como comércio, consumo de bens, serviços e energia, renda familiar, etc.

- DIMENSÃO AMBIENTAL - Indicadores formulados a partir de características ambientais que 
promovam o equilíbrio e a preservação ambiental, como cobertura vegetal, qualidade de recursos naturais (solo, ar, água, etc.), conservação da fauna, etc.

- DIMENSÃO INSTITUCIONAL - Indicadores baseados na ação do poder público na promoção do desenvolvimento sustentável, implementação e monitoramento do desenvolvimento sustentável, preparo e resposta a desastres naturais, etc.

Entretanto, os pesquisadores que criaram a metodologia do Painel da Sustentabilidade, generalizaram os indicadores, tornando alguns deles inaplicáveis a determinados locais ou até mesmo, desconsiderando certas particularidades da escala de trabalho.

O tipo de abordagem na seleção dos indicadores, também pode funcionar como um fator limitante em sua formulação. Existem dois tipos de abordagem, a top-down ${ }^{1}$ bottom-u ${ }^{2}$. Cada tipo de abordagem possui vantagens e desvantagens, mas a sua escolha fica a critério das condições onde irá ser implementado.

Outro elemento essencial para que seja garantida a confiabilidade na construção do sistema de indicadores e índices de sustentabilidade é a sua legitimidade, pois é baseada nela que serão criados os subsídios para a efetivação do processo decisório.

Para que a mensuração da tendência da sustentabilidade local seja compatível com a área de estudo selecionada, é necessário identificar o background a partir das especificidades locais. No caso desta tese, um ambiente urbano já consolidado é compatível com o Índice de Sustentabilidade Urbana (ISU).

Contudo, a multiplicidade de abordagens sobre o termo Sustentabilidade também reflete na sua forma de mensuração. Dependendo do contexto focado pelo pesquisador, o ISU pode apresentar indicadores diferentes. Por exemplo, Silveira (2005) enfoca o levantamento deste índice através de indicadores de conforto bioclimático decorrente morfologia urbana, já para Xavier (2009), esse índice é representado por mensurar o grau de sustentabilidade urbana dos empreendimentos e para Martinez e Leiva, (2003) o índice deve conter a possibilidade de analisar desde a estrutura da cidade até o comportamento daqueles que vivem, transitam e usufruem da cidade, bem como analisar e identificar oportunidades e deficiências, além de acompanhar a implementação e os impactos das estratégias propostas.

Assim, esta pesquisa, buscando definir uma metodologia de mensuração da tendência da sustentabilidade reunindo elementos característicos do Dashboard Sustainability, manteve o foco da sustentabilidade urbana sob a perspectiva dos indicadores de harmonia entre os recursos hídricos (rios urbanos) e as diretrizes de zoneamento, controle e desenvolvimento urbano.

Este trabalho levanta uma hipótese. De que através da criação e avaliação de um índice de sustentabilidade em um ambiente urbano já consolidado, e destacando o desempenho de indicadores institucionais, é possível subsidiar elementos técnico-científicos para a promoção da sustentabilidade local, através da conservação e transformação da paisagem fluvial urbana.

Contudo, é preciso salientar que os rios percorrem diversos bairros da cidade e que possuem perfis socioeconômicos diferenciados, impactando de diferentes formas o corpo hídrico.

1 Top-down - Pesquisadores definem o sistema e o grupo de indicadores, que serão utilizados pelos tomadores de decisão, no caso o poder público e a sociedade, podendo ainda optar por adaptar as determinações dos pesquisadores às condições locais, mas não tem autonomia para alterar nada. A vantagem desse tipo de abordagem é a proximidade de validação científica e homogênea em termos de indicadores. A desvantagem é a nulidade do contato com as prioridades da comunidade.

2 Bottom-up - As escolhas são realizadas de forma participativa com a comunidade, líderes comunitários e representantes do poder público, consolidando as decisões finais em consultas aos especialistas. O uso dessa abordagem é comum em escalas regionais e locais, pois envolve a comunidade como fonte primária na identificação de suas prioridades. A desvantagem é a limitação do foco na sustentabilidade, pois existe a possibilidadelatente na priorização de aspectos emergenciais ou de curto prazo, levando a omissão de diretrizes cruciais para os demais aspectos da sustentabilidade. 
O propósito é demonstrar que através da mensuração da sustentabilidade local a partir do monitoramento dos cursos d'água e seus indicadores sociais, econômicos e institucionais, pelo painel da sustentabilidade (Dashboard Sustainability), que é possível estabelecer uma metodologia de gestão e planejamento dos recursos hídricos urbanos que integre as diretrizes legais de proteção dos rios e do desenvolvimento da cidade através das três bacias hidrográficas estudadas.

\section{Material e mÉtodos}

O trabalho foi desenvolvido nos territórios que compõem três bacias hidrográficas urbanas dos rios Jaguaribe, Cuiá e Cabelo, que cortam a cidade de João Pessoa - PB de norte a sul, sendo estas áreas escolhidas por conter limites geográficos bem definidos e facilmente identificados e ainda por apresentarem importância estratégica para diversas relações sociais e econômicas da cidade além de sua relevância na conservação de ecossistemas costeiros.

Para análise da política urbana municipal desta rede hidrográfica, foram consideradas as duas últimas versões dos planos diretores de João Pessoa, as versões de 1992 e de 2009. Observando a evolução e a introdução das diretrizes preconizadas, e todos os planos nacionais apresentados anteriormente, o plano diretor de 2009 já deveria apresentar alterações que atendessem todas as diretrizes dos Planos Nacionais.

Mesmo que haja o destaque no Plano Municipal de que essas áreas são classificadas com ZEP's na forma das Leis Federal e Estadual, a responsabilidade recai sobre a gestão municipal no cumprimento das diretrizes de preservação desses ambientes mediante a inserção de outros mecanismos de zoneamento ambiental, que foram apresentados posteriormente, pois foi feito um comparativo entre as diretrizes legais apresentadas nos planos nacionais e indicadas as falhas no PD de João Pessoa.

Foram identificados e em seguida selecionados, de acordo com as possibilidades técnicas de pesquisa, grupos de indicadores gerais que podem ser subdivididos em indicadores específicos, de acordo com as características relevantes dos territórios estudados.

O método construção do trabalho seguiu as seguintes etapas:

\section{ETAPA 1}

Identificação e caracterização da área de estudo, que têm por finalidade conhecer “in loco" as principais características do local (vegetação, uso do solo, qualidade dos recursos hídricos, ocupação urbana, oferta de serviços públicos, etc), fazendo uso de visitas ao local, de modo a fornecer subsídios para a escolha do método de gestão e planejamento a ser aplicado.

\section{ETAPA 2}

A estrutura para a avaliação de escolha do método de planejamento foi baseada na forma de Pressão Estado - Resposta, havendo a necessidade da verificação dos Indicadores de Pressão, Indicadores de Estado e Indicadores de Resposta à que a área está submetida e dessa forma, atendendo as principais características de confiabilidade, facilidade de entendimento, mensuração e relevância para posteriores ações políticas; 


\section{ETAPA 3}

Coleta e análise de dados primários. A coleta dos dados primários em campo e em gabinete é foi a etapa que forneceu parâmetros quantitativos e qualitativos das principais características ambientais, econômicas e sociais e que posteriormente compuseram os indicadores de sustentabilidade. Esses dados primários foram obtidos após a avaliação dos fatores aplicáveis a área de estudo.

Um dos dados primários levantados foram os parâmetros qualitativos da água dos rios e dos gradientes de umidade relativa do ar e temperatura, de pontos distribuídos ao longo dos cursos desde as nascentes até sua desembocadura, procurando identificar suas principais características físico-químicas e que tem relação com os demais indicadores sociais, econômicos, ambientais e institucionais escolhidos para a pesquisa.

\section{ETAPA 4}

Todos os rios escolhidos baseiam-se no princípio de que estes possuem uma relação intrínseca com os indicadores de desenvolvimento urbano e possuem nascente e desembocadura dentro do perímetro de João Pessoa. O levantamento dos demais indicadores seguirá a uma metodologia de consulta aos documentos do setor Censitário Urbano do IBGE e ao sistema da Gerência de Epidemiologia e Saúde da Prefeitura Municipal de João Pessoa, o qual segue o tutorial (Figura 2).

Figura 2 - Fluxograma do tutorial de consulta à base de dados do IBGE.

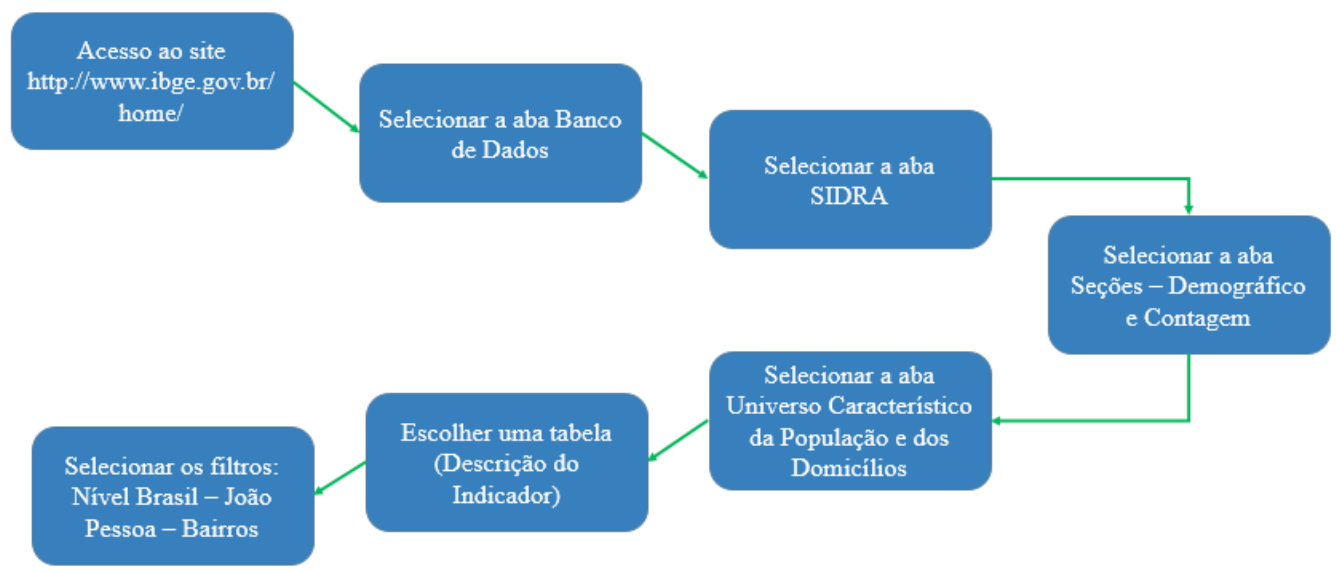

Através do uso do software de geoprocessamento (Q-Gis), foi realizada a identificação dos limites topográficos de cada bacia hidrográfica, percurso dos rios e dos bairros de João Pessoa que estão inseridos na respectiva bacia hidrográfica. Através dessas informações foi possível elaborar através de imagens de satélite, a representação das estações de coleta de amostras mensais da qualidade da água, a identificação dos impactos locais críticos em relação à degradação ambiental, bem como facilitar a consulta a base de dados do IBGE, na identificação geoespacial dos indicadores.

\section{ETAPA 5}

Identificação e atribuição de Indicadores e Índices de Sustentabilidade. Nessa etapa de identificação dos Indicadores, foi feita uma avaliação multicriterial e multidisciplinar dos dados primários. Essa avaliação fornece especificações mensuráveis e caracterizada pelos Indicadores de Sustentabilidade.

Foram identificados na pesquisa 19 indicadores (Quadro 1) de modo a dimensionar de maneira integrada o universo de análise segundo a base do IBGE do último censo de 2010 e de indicadores coletados “in loco". 
Quadro 1 - Dimensões e indicadores

\begin{tabular}{|c|c|c|}
\hline DIMENSÕES & & INDICADORES \\
\hline \multirow{4}{*}{ Institucional } & I1 & Implementação e Monitoramento do Desenvolvimento Sustentável \\
\hline & $\mathrm{I} 2$ & Monitoramento de Áreas de Preservação Permanente \\
\hline & $\mathrm{I3}$ & Preparo e Resposta a Desastres Naturais \\
\hline & I4 & Planejamento e Acesso a Informações \\
\hline \multirow{4}{*}{ Ambiental } & A1 & $\begin{array}{l}\text { Domicílios particulares permanentes - abastecimento de água - Rede geral (Taxa de } \\
\text { domicílios que tem acesso a água) }\end{array}$ \\
\hline & A2 & $\begin{array}{l}\text { Domicílios particulares permanentes - tipo de saneamento - total - adequado - } \\
\text { Acesso ao esgotamento sanitário (Taxa) }\end{array}$ \\
\hline & A3 & Domicílios particulares permanentes - destino do lixo - Coletado (taxa) \\
\hline & A4 & Parâmetros de Qualidade da água \\
\hline \multirow{5}{*}{ Social } & S1 & $\begin{array}{l}\text { Taxa de notificações por doenças de transmissão e veiculação hídrica (Fonte: } \\
\text { Secretaria de Saúde do Município de João Pessoa) }\end{array}$ \\
\hline & S2 & Adensamento Populacional \\
\hline & S3 & Taxa de domicílios com um ou mais banheiros \\
\hline & $\mathrm{S} 4$ & Taxa de domicílios com energia elétrica fornecida por distribuidora \\
\hline & S5 & Taxa de Alfabetização per capta \\
\hline \multirow{6}{*}{ Econômica } & E1 & $\begin{array}{l}\text { Classes de rendimento nominal mensal domiciliar per capita até } 1 / 4 \text { de salário mínimo } \\
\text { (taxa IBGE). }\end{array}$ \\
\hline & $\mathbf{E} 2$ & $\begin{array}{l}\text { Classes de rendimento nominal mensal domiciliar per capita entre } 1 / 4 \text { e } 1 / 2 \text { Salário } \\
\text { Mínimo (taxa IBGE). }\end{array}$ \\
\hline & E3 & $\begin{array}{l}\text { Classes de rendimento nominal mensal domiciliar per capita entre } 1 / 2 \text { e } 1 \text { Salário } \\
\text { Mínimo (taxa IBGE). }\end{array}$ \\
\hline & E4 & $\begin{array}{l}\text { Classes de rendimento nominal mensal domiciliar per capita entre } 2 \text { e } 3 \text { salários } \\
\text { Mínimos (taxa IBGE). }\end{array}$ \\
\hline & E5 & $\begin{array}{l}\text { Classes de rendimento nominal mensal domiciliar per capita entre } 3 \text { e } 5 \text { salários } \\
\text { Salários Mínimos (taxa IBGE). }\end{array}$ \\
\hline & E6 & $\begin{array}{l}\text { Classes de rendimento nominal mensal domiciliar per capita }>5 \text { Salários Mínimos } \\
\text { (taxa IBGE). }\end{array}$ \\
\hline
\end{tabular}

\section{ETAPA 6}

A união dos vários indicadores de sustentabilidade institucional, ambiental, social e econômica fornece o Índice de Sustentabilidade específico da área estudada, sem que ocorra o isolamento com as demais áreas de abrangência da bacia hidrográfica, respeitando quatro critérios gerais: Relevância para ações políticas, utilidade para usuários, fundamentação técnica e facilidade de medição.

\section{ETAPA 7}

Para cada dimensão da sustentabilidade foi atribuído um peso igual ${ }^{3}$, (tendo em vista, não haver consenso dos pesquisadores quanto às atribuições de pesos para os indicadores) de acordo com o número de indicadores identificados na área de estudo, dessa forma foi possível qualificar a tendência de sustentabilidade do local de acordo com a pontuação multicriterial, onde 100 é excelente (valor máximo) e 0 é o Estado Crítico (valor mínimo) e sua tendência é dada pela fórmula $100 *(\mathrm{X}$ - pior)/(melhor- pior), onde $\mathrm{X}$ é a média do valor bruto dos dados primários, pior é o menor valor em módulo constante e melhor é o maior valor em módulo constante;

3 A atribuição de pesos iguais entre as dimensões da sustentabilidade segue a metodologia do Painel da Sustentabilidade descrito por VanBellen, 2006. 


\section{ETAPA 8}

Criação do Painel de Sustentabilidade. Após obter os resultados quantitativos da avaliação de desempenho dos indicadores foi criada uma relação entre esses valores e um gradiente de cores que vai do verde escuro, que representa a maior nota, ao vermelho escuro, que representa a menor nota de acordo com a Quadro 2:

Quadro 2 - Relação entre pontuação e gradiente de cores.

\begin{tabular}{|c|c|c|c|}
\hline Intervalo de Pontuação & Gradiente de Cores & Intervalo de Pontuação & Gradiente de Cores \\
\hline $0-10$ & & $51-60$ & \\
\hline $11-20$ & $\square$ & $61-70$ & \\
\hline $21-30$ & $\square$ & $71-80$ & \\
\hline $31-40$ & $\square$ & $81-90$ & \\
\hline $41-50$ & $\square$ & $91-100$ & \\
\hline
\end{tabular}

\section{Resultados dos indicadores por bacia hidrográfica}

Os resultados da qualidade da água dos rios pesquisados, limitaram-se a analisar os mesmos parâmetros monitorados pelo órgão de fiscalização do Estado (SUDEMA), distribuindo os pontos de coleta ao longo do curso dos rios, onde haviam duas condições básicas, facilidade de acesso localização dos impactos ambientais urbanos ou confluências dos rios. Já os demais indicadores tiveram sua base de dados primários informações obtidas em órgãos públicos de controle, a exemplo do IBGE e PMJP.

As características climáticas observadas durante um ano de atividades de campo, que foram monitoradas através de um termo higrômetro, indicam que o gradiente de temperatura e umidade relativa do ar, medidas nos pontos de coleta ao longo das bacias, são diferentes da média para João Pessoa, com temperaturas acima da média da cidade e umidade relativa abaixo.

A média de temperatura atmosférica encontrada nas 3 bacias hidrográficas estudadas é um gradiente que varia entre $31,0 \mathrm{C}^{\circ}$ a $32,5 \mathrm{C}^{\circ}$ e a média da umidade relativa do ar, ficou em torno de $38,4 \%$. Valores significativamente diferentes do gradiente geral da cidade de João Pessoa, aferido pela estação do INMET. Havendo a possiblidade desses valores estarem relacionados aos aspectos de intervenção urbana nos pontos coletados, indicando características de um microclima nas bacias.

\section{Rio Cabelo}

Em relação aos aspectos qualitativos da água do rio Cabelo, segundo o monitoramento feito durante a pesquisa, os dados indicam que a maior parte do rio sofre com a degradação urbana desde sua nascente até a sua foz devido a efluentes domésticos.Na nascente, as características físico-químicas, microbiológicas e ambientais indicam contaminação permanente e muito antiga de ligações clandestinas de esgotos domésticos. 
Caminhando mais adiante no curso do rio, foi possível encontrar outros impactos que contribuem para a completa descaracterização natural do rio em relação a sua qualidade.Impactos como criação de animais, erosão de barreiras e assoreamento, captação indevida da água feita por carros pipa, lançamento de efluente bruto da CAGEPA e todos esses impactos alterariam o enquadramento do rio bem como os aspectos ecológicos envolvidos em um corpo hídrico.

Apenas um pequeno trecho do rio compreendido no médio curso, sofre um pouco menos os efeitos da urbanização, devido à dificuldade de acesso por causa da mata, contudo, a qualidade da água do rio está quase que totalmente comprometida, segundo o monitoramento feito durante a pesquisa.

A região que abrange a micro bacia do Rio Cabelo apresenta-se fortemente impactada por interferências antrópicas diversas, decorrentes da expansão urbana. Segundo Sassi et al., (1997), na nascente existe uma vegetação em sua maioria rasteira com arvores de porte médio e onde se encontram indícios de degradação devido à proximidade de áreas urbanas mais adensadas pela população que retiram madeira para queima, plantio de algumas culturas de frutas, criação de animais e disposição de resíduos sólidos.

A bacia hidrográfica do rio Cabelo tem aproximadamente $9,71 \mathrm{Km}^{2}$, limita-se ao norte com a bacia do Jaguaribe, ao sul com a do Cuiá e Aratu, a oeste com a do Cuiá e a leste com o oceano Atlântico, no qual deságua (Figura 3).

Os pontos em vermelho na Figura 3, localizam as estações de coleta de dados primários de campo que foram determinados, de acordo com localização dos principais fatores que marcam o curso do rio, como a confluência com um de seus afluentes.

Figura 3 - Recorte da bacia hidrográfica do rio Cabelo.

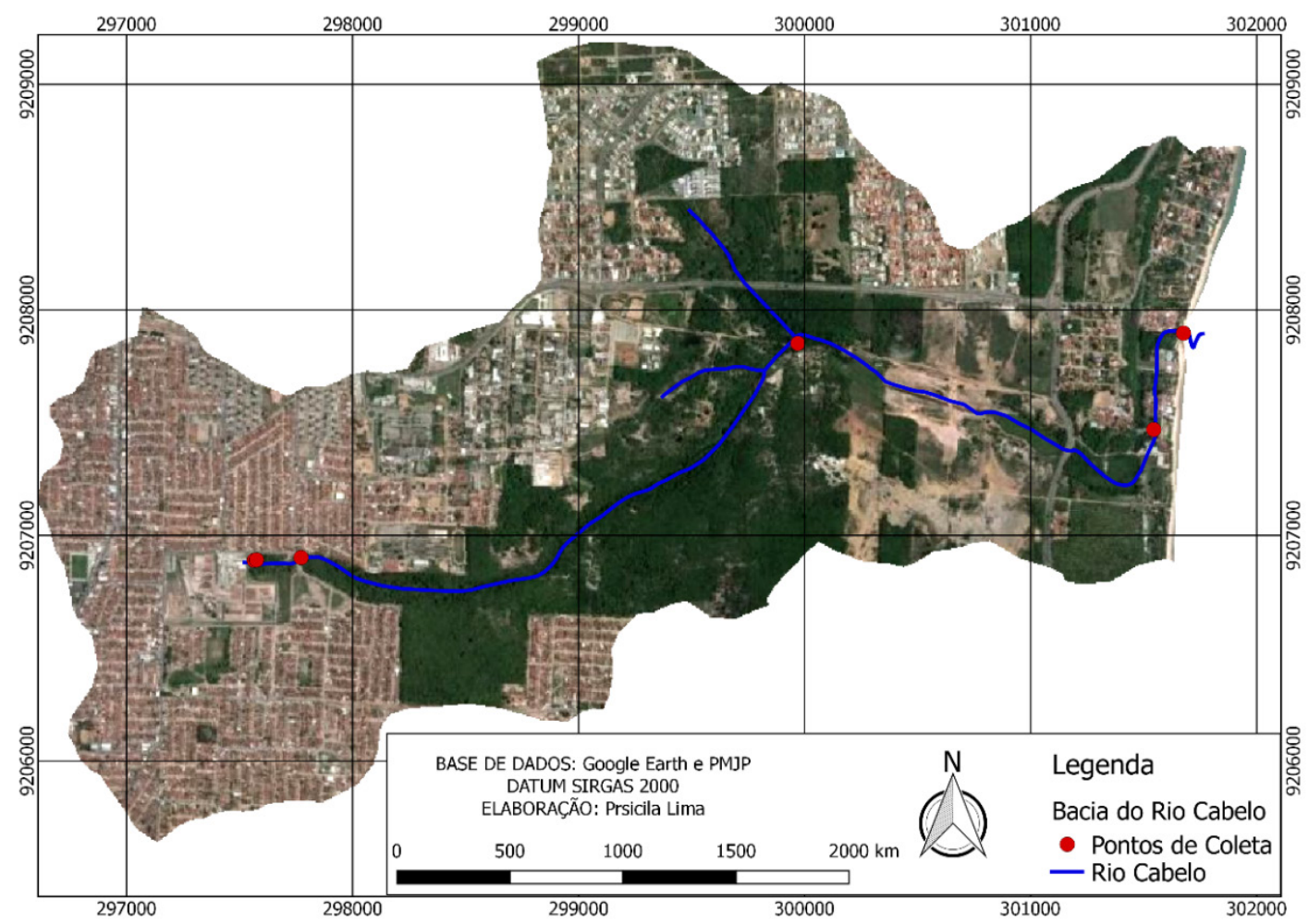

Fonte: Elaboração - Priscila Lima, 2016.

De maneira global, o desempenho dos indicadores da bacia hidrográfica do rio Cabelo é bem diversificado (Quadro 3). 
Quadro 3 - Desempenho dos Indicadores de Sustentabilidade do rio Cabelo

\begin{tabular}{|c|c|c|c|}
\hline DIMENSÕES & INDICADORES & NOTA & COR \\
\hline \multirow{4}{*}{ Ambiental } & $\begin{array}{l}\text { Domicílios particulares permanentes - abastecimento de água - Rede } \\
\text { geral }\end{array}$ & 95 & \\
\hline & Parâmetros de Qualidade da água & 12 & \\
\hline & $\begin{array}{l}\text { Domicílios particulares permanentes - tipo de saneamento - total - } \\
\text { adequado - Acesso ao esgotamento sanitário (Taxa) }\end{array}$ & 69 & \\
\hline & $\begin{array}{l}\text { Domicílios particulares permanentes } \\
\text { - Destino do lixo - Coletado (taxa) }\end{array}$ & 99 & \\
\hline \multirow{4}{*}{ Institucional } & Implementação e Monitoramento do Desenvolvimento Sustentável & 35 & \\
\hline & Monitoramento de Áreas de Preservação Permanente & 22 & \\
\hline & Preparo e Resposta a Desastres Naturais & 7 & \\
\hline & Planejamento e Acesso a Informações & 7 & \\
\hline \multirow{5}{*}{ Social } & Notificações por doenças de transmissão e veiculação hídrica & 80 & \\
\hline & Adensamento Populacional & 100 & \\
\hline & Taxa de domicílios com um ou mais banheiros & 99 & \\
\hline & Domicílios com energia elétrica fornecida por distribuidora & 99 & \\
\hline & Taxa de Alfabetização per capta & 87 & \\
\hline \multirow{7}{*}{ Econômica } & $\begin{array}{l}\text { Classes de rendimento nominal mensal domiciliar per capita até } 1 / 4 \text { de } \\
\text { salário mínimo (taxa). }\end{array}$ & 93 & \\
\hline & $\begin{array}{l}\text { Classes de rendimento nominal mensal domiciliar per capita entre } 1 / 4 \mathrm{e} \\
1 / 2 \text { salário mínimo (taxa). }\end{array}$ & 80 & \\
\hline & $\begin{array}{l}\text { Classes de rendimento nominal mensal domiciliar per capita entre } 1 / 2 \mathrm{e} \\
\qquad 1 \text { salário mínimo (taxa). }\end{array}$ & 64 & \\
\hline & $\begin{array}{l}\text { Classes de rendimento nominal mensal domiciliar per capita entre } 1 \text { e } \\
\qquad 2 \text { salários mínimos (taxa). }\end{array}$ & 25 & \\
\hline & $\begin{array}{l}\text { Classes de rendimento nominal mensal domiciliar per capita entre } 2 \text { e } \\
\qquad 3 \text { salários mínimos (taxa). }\end{array}$ & 6 & \\
\hline & $\begin{array}{l}\text { Classes de rendimento nominal mensal domiciliar per capita entre } 3 \text { e } \\
\qquad 5 \text { salários mínimos (taxa). }\end{array}$ & 4 & \\
\hline & $\begin{array}{l}\text { Classes de rendimento nominal mensal domiciliar per capita }>5 \text { salá- } \\
\text { rios mínimos (taxa). }\end{array}$ & 2 & \\
\hline
\end{tabular}


O pior indicador da dimensão ambiental é o de qualidade da água, já evidenciado pelo monitoramento realizado durante um ano de campanhas de coleta. Os impactos identificados para que este indicador tenha uma baixa performance é o lançamento de agentes poluentes proveniente de ligações clandestinas de esgoto doméstico pela população e até mesmo o lançamento indevido de esgoto bruto pela CAGEPA, quando as estações elevatórias não suportam a vazão de esgoto que deveria ser recalcado para a estação de tratamento de efluentes em Mangabeira.

Os indicadores da dimensão Institucional apresentam o pior desempenho em todas as situações estudadas. Em resumo, como são indiciadores universais e suas ações focam não somente o território de uma bacia hidrográfica específica, mas para todo o município de João Pessoa, a avaliação é ampliada e replicada para todos os locais estudados. O motivo pelo qual esse indicador apresenta uma baixa performance é a impossibilidade de evidenciar a existência de estruturas operacionais que viabilizem a execução das diretrizes dos indicadores, ou seja, não há evidencia, segundo critérios legais ou institucionais da operacionalização desses indicadores.

$\mathrm{Na}$ dimensão Social, todos os indicadores apresentam um bom desempenho segundo os dados do IBGE, contudo é importante ressaltar que quanto melhor o desempenho em uma dimensão, maior pode ser a pressão no indicador de outra dimensão. Nesse caso em específico, a relação entre a taxa de domićlios com banheiros é bem elevada, com 99 pontos, já a taxa de domicílios que tem o esgoto ligado à rede geral apresenta 69 pontos, cerca de menos de 50\% dos domićlíos, consequentemente, esse esgoto gerado e não coletado pela rede pública gera impactos nos rios, sendo lançados indevidamente, gerando um desempenho muito baixo do indicador de qualidade da água.

O indicador de notificações de doenças de transmissão e veiculação hídrica identificado na bacia do rio Cabelo teve um bom desempenho, pois houveram poucas notificações de ocorrências relativas a esse tipo de doença, contudo, vale ressaltar a possibilidade dasestatísticas não estarem compatíveis com a realidade.

Já na dimensão econômica, o desempenho dos indicadores foi realizar a avaliação de maneira a observar o total da população presente no território, pela população por cada faixa de renda, sendo positivo, o menor número de pessoas com rendimento inferior a 1 salário mínimo e/ou o maior número de pessoas com rendimento superior a 1 salário mínimo. E sendo negativo o maior número de pessoas com rendimentos abaixo de 1 salário e o menor número de pessoas com rendimentos acima de um salário.

O desempenho geral deste indicador mostra a avaliação da distribuição de renda, a linha de tendência sinaliza uma má distribuição de renda, onde uma maior parte da população tem menores rendimentos, e que no caso específico da bacia hidrográfica do rio Cabelo, a faixa de rendimento entre 1 e 2 salários, que seria a faixa intermediária entre o pior rendimento e o melhor rendimento apresenta uma pontuação de 25 pontos, indicando que o quantitativo de pessoas que recebem nessa faixa de renda é relativamente baixo, mas precisa melhorar. Já o desempenho do indicador das pessoas que recebem numa faixa de renda de até $1 / 4$ de salário (pior faixa salarial) é considerado alto, pois poucas pessoas recebem esse valor, e os que recebem acima de 5 salários (melhor faixa salarial) é baixo, pois poucas pessoas recebem esse valor (Figura 4 e Quadro 3).

Rio Cuiá

A bacia hidrográfica do rio Cuiá está localizada na Mesorregião do Litoral Paraibano e na Microrregião de João Pessoa, no Município de João Pessoa, na parte sul do litoral Paraibano, limita-se ao norte com as bacias 
dos rios Jacarapé, Aratu e Jaguaribe, ao sul com a bacia do rio Gramame, ao oeste com a bacia do rio Paraíba e a leste com o oceano, onde desagua.

A principal nascente do rio Cuiá está localizada no conjunto habitacional do Grotão desaguando na planície costeira da Praia do Sol.

Um dos principais afluentes do rio Cuiá é o riacho Laranjeiras localizado na sua margem esquerda e o riacho Buracão localizado na sua margem direita. Além desses riachos há um grande número de córregos e ressurgências naturais que garantem a sua perenização, mantendo uma vazão regular durante o ano todo.

Ao longo de seu percurso de aproximadamente $10 \mathrm{~km}$, o mesmo segue o sentido Oeste/Leste, até desaguar no Oceano Atlântico na Praia do Sol onde se forma um ecossistema estuarino-lagunar.

Por estar totalmente inserida no meio urbano e permeada por bairros altamente populosos (Figura4).

A bacia do rio Cuiá, apresenta características ambientais e paisagísticas profundamente alteradas como fator agravante, a própria expansão dos conjuntos habitacionais após os anos 70, que se intensificou nos anos 80 e 90 e mais recentemente a aprovação de inúmeros loteamentos, consolidou as alterações da sua fisionomia.

Diversos impactos ambientais foram identificados no curso do rio Cuiá, impactos que vão desde lançamento clandestino de efluentes domésticos ou vazamento nas tubulações das estações elevatórias da CAGEPA, assoreamento, construções nas margens do rio, desmatamento, sendo que esses impactos ambientais, refletem a vulnerabilidade institucional do poder público municipal e estadual, na ausência de ações de preservação e de proteção ao meio ambiente urbano.

Figura 4 - Recorte da Bacia Hidrográfica do rio Cuiá

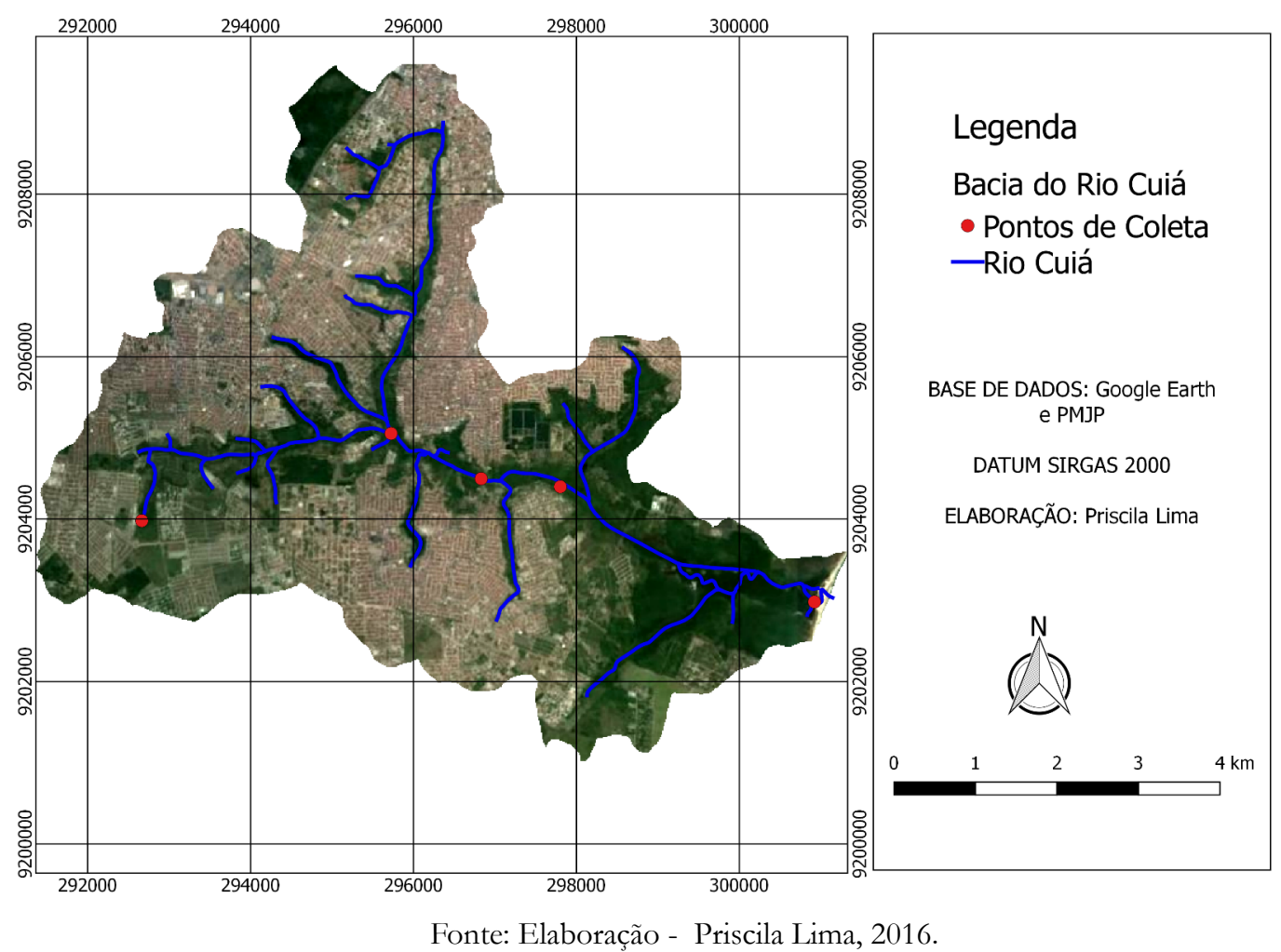

De maneira global, o desempenho dos indicadores da bacia hidrográfica do rio Cuiá segue a tendência da performance dos indicadores da bacia hidrográfica do rio Cabelo, constando apenas algumas diferenças numéricas da pontuação dos indicadores (Quadro 4). 
Quadro 4 - Desempenho dos Indicadores de Sustentabilidade do rio Cuiá

\begin{tabular}{|c|c|c|c|}
\hline DIMENSÕES & INDICADORES & NOTA & COR \\
\hline \multirow{4}{*}{ Ambiental } & $\begin{array}{l}\text { Domicílios particulares permanentes - abastecimento de água - Rede } \\
\text { geral }\end{array}$ & 97 & \\
\hline & Parâmetros de Qualidade da água & 39 & \\
\hline & $\begin{array}{l}\text { Domicílios particulares permanentes - tipo de saneamento - total - } \\
\text { adequado - Acesso ao esgotamento sanitário (Taxa) }\end{array}$ & 49 & \\
\hline & $\begin{array}{l}\text { Domicílios particulares permanentes } \\
\text { - Destino do lixo - Coletado (taxa) }\end{array}$ & 99 & \\
\hline \multirow{4}{*}{ Institucional } & Implementação e Monitoramento do Desenvolvimento Sustentável & 35 & \\
\hline & Monitoramento de Áreas de Preservação Permanente & 22 & \\
\hline & Preparo e Resposta a Desastres Naturais & 7 & \\
\hline & Planejamento e Acesso a Informações & 7 & \\
\hline \multirow{5}{*}{ Social } & Notificações por doenças de transmissão e veiculação hídrica & 75 & \\
\hline & Adensamento Populacional & 100 & \\
\hline & Taxa de domicílios com um ou mais banheiros & 99 & \\
\hline & Domicílios com energia elétrica fornecida por distribuidora & 99 & \\
\hline & Taxa de Alfabetização per capta & 88 & \\
\hline \multirow{7}{*}{ Econômica } & $\begin{array}{l}\text { Classes de rendimento nominal mensal domiciliar per capita até } 1 / 4 \text { de } \\
\text { salário mínimo (taxa). }\end{array}$ & 90 & \\
\hline & $\begin{array}{l}\text { Classes de rendimento nominal mensal domiciliar per capita entre } 1 / 4 \mathrm{e} \\
\qquad 1 / 2 \text { salário mínimo (taxa). }\end{array}$ & 80 & \\
\hline & $\begin{array}{l}\text { Classes de rendimento nominal mensal domiciliar per capita entre } 1 / 2 \mathrm{e} \\
\qquad 1 \text { salário mínimo (taxa). }\end{array}$ & 68 & \\
\hline & $\begin{array}{l}\text { Classes de rendimento nominal mensal domiciliar per capita entre } 1 \text { e } \\
\qquad 2 \text { salários mínimos (taxa). }\end{array}$ & 25 & \\
\hline & $\begin{array}{l}\text { Classes de rendimento nominal mensal domiciliar per capita entre } 2 \text { e } \\
\qquad 3 \text { salários mínimos (taxa). }\end{array}$ & 7 & \\
\hline & $\begin{array}{l}\text { Classes de rendimento nominal mensal domiciliar per capita entre } 3 \text { e } \\
\qquad 5 \text { salários mínimos (taxa). }\end{array}$ & 4 & \\
\hline & $\begin{array}{c}\text { Classes de rendimento nominal mensal domiciliar per capita }>5 \text { salá- } \\
\text { rios mínimos (taxa). }\end{array}$ & 3 & \\
\hline
\end{tabular}


O pior indicador da dimensão ambiental é o de qualidade da água, já evidenciado pelo monitoramento realizado durante um ano de campanhas de coleta. Os impactos identificados para que este indicador tenha uma baixa performance é o lançamento de agentes poluentes proveniente de ligações clandestinas de esgoto doméstico pela população e até mesmo o lançamento indevido de esgoto bruto pela CAGEPA, quando as estações elevatórias não suportam a vazão de esgoto que deveria ser recalcado para a estação de tratamento de efluentes em Mangabeira.

Outro fator muito impactante na qualidade da água do rio Cuiá que precisa ser ressaltado é que o rio Cuiá é o corpo hídrico urbano destinado a receber o efluente tratado, proveniente da ETE de Mangabeira ${ }^{4}$.

Após realizar o monitoramento da qualidade da água do rio Cuiá, fica evidente a influência negativa do lançamento do efluente tratado nas atuais condições em que o rio se encontra. Desde sua nascente, o rio Cuiá encontra - se em uma situação crítica, pois os parâmetros de monitoramento já indicam através da média anual, que estão em desacordo com as diretrizes previstas pelo enquadramento do CONAMA no 357.

Ao longo do curso do rio, onde estão dispostas outras estações de monitoramento, o gradiente de variação de qualidade da água é pequeno, pois são identificados outros impactos que potencializam a poluição ao longo do rio, como assoreamento e lançamento clandestino de efluentes domésticos.

Assim, duas estações de monitoramento estão localizadas a 50 metros a montante e 50 metros a jusante da zona de mistura do efluente tratado da ETE de Mangabeira, contudo o efluente tratado apenas aumenta o potencial de poluição já identificado em trechos anteriores ao rio.

Como apresentado nas figuras anteriormente, onde as tubulações de recalque das estações elevatórias lançam frequentemente esgoto bruto. Ainda a montante da zona de lançamento da ETE de Mangabeira, o rio já apresenta características de eutrofização, com a presença de vegetação aquática em excesso e já na zona de mistura da estação o efluente tratado é lançado no rio com uma falha quantitativa, ou seja, não há qualquer controle da vazão do efluente lançado, o controle é apenas qualitativo.

Independente da vazão do rio, a vazão de efluente tratado é lançada no corpo hídrico. E como existe a tendência de aumento da zona urbana consolidada (com serviços de coleta e transporte de esgoto e de domićlíos ligados a rede geral de abastecimento de água, número de domicílios com banheiro e coleta de resíduos sólidos - Indicadores ambientais e sociais) e do adensamento demográfico (indicador social) na região da bacia hidrográfica do Cuiá e das bacias adjacentes a ela, a condição da qualidade da água do rio torna-se mais crítica, pois os fatores que impactam na redução qualitativa e quantitativa na vazão do rio e dos fatores que impactam no aumento da vazão do efluente, reduz drasticamente a capacidade de depuração do efluente e desta forma comprometendo a qualidade da função ecossistêmica fornecida pelo rio Cuiá.

Os demais indicadores ambientais apresentam um desempenho positivo segundo os dados do IBGE e apresentados no Quadro 4, exceto a taxa de domicílios com acesso a rede de esgotamento sanitário, que como a tendência das demais bacias estudadas fica abaixo dos 50 pontos.

Os indicadores da dimensão Institucional já foram discutidos anteriormente, pois devido sua natureza de indiciadores universais e suas ações focam não somente o território de uma bacia hidrográfica específica, mas para todo o município de João Pessoa, a avaliação é ampliada e replicada para todos os locais estudados. Assim, o desempenho dessa dimensão é muito baixo devido a impossibilidade de evidenciar a existência de estruturas operacionais que viabilizem a execução das diretrizes dos indicadores, ou seja, não há evidência, segundo critérios legais ou institucionais da operacionalização desses indicadores.

4 Essa definição está descrita no plano diretor municipal apresentada no referencial teórico deste trabalho. 
Por exemplo, como apresentado anteriormente, problemas constantes de inundação da ponte que divide os bairros de Mangabeira e Valentina, causando transtornos aos moradores locais. Isso sinaliza a omissão do poder público em ocorrências já previstas no período de chuvas e onde a ação é apenas paliativa, no desassoreamento daquele trecho do curso d'água, sem haver a real solução da causa do problema, apenas atuando em seus efeitos pontuais.

$\mathrm{Na}$ dimensão Social, todos os indicadores apresentam um bom desempenho segundo os dados do IBGE, contudo é importante ressaltar que quanto melhor o desempenho em uma dimensão, maior pode ser a pressão no indicador de outra dimensão. Nesse caso em específico, a relação entre a taxa de domicílios com banheiros é bem elevada, com 99 pontos, já a taxa de domicílios que tem o esgoto ligado à rede geral apresenta 49 pontos, cerca de menos de 50\% dos domicílios, consequentemente, esse esgoto gerado e não coletado pela rede pública gera impactos nos rios, sendo lançados indevidamente, gerando um desempenho muito baixo do indicador de qualidade da água.

O indicador de notificações de doenças de transmissão e veiculação hídrica identificado na bacia do rio Cuiá teve um bom desempenho, pois houveram poucas notificações de ocorrências relativas a esse tipo de doença, contudo, vale ressaltar a possibilidade das estatísticas não estarem compatíveis com a realidade.

Já na dimensão econômica, o desempenho dos indicadores seguiu o mesmo mecanismo das demais bacias hidrográficas analisadas, avaliando o total da população presente no território, pela população por cada faixa de renda, sendo positivo, o menor número de pessoas com rendimento inferior a 1 salário mínimo e/ou o maior número de pessoas com rendimento superior a 1 salário mínimo. E sendo negativo o maior número de pessoas com rendimentos abaixo de 1 salário e o menor número de pessoas com rendimentos acima de um salário.

O desempenho geral deste indicador mostra os dados apresentados no gráfico 1, onde na avaliação da distribuição de renda, a linha de tendência sinaliza uma má distribuição de renda, onde uma maior parte da população tem menores rendimentos, e que no caso específico da bacia hidrográfica do rio Cuiá, a faixa de rendimento entre 1 e 2 salários, que seria a faixa intermediária entre o pior rendimento e o melhor rendimento apresenta uma pontuação de 25 pontos, semelhante a tendência da bacia hidrografia do rio Cabelo.

Rio Jaguaribe

O Jaguaribe é o mais extenso rio urbano da capital paraibana, com cerca de 21 quilômetros de extensão e $60 \mathrm{Km}^{2}$, tem sua nascente localizada nas imediações do bairro de Oitizeiro, nas proximidades da região das 3 Lagoas. O curso do rio cruza praticamente a cidade de João Pessoa de norte a sul e relembrando o tópico da história da expansão urbana, abordado no referencial teórico desta tese, o rio Jaguaribe, é um fator natural que serviu como limitante do crescimento urbano, e sua história é marcada por profundas alterações quantitativas e qualitativas em seu curso. Algumas dessas alterações foram planejadas de acordo os interesses de ordenamento territorial e outras por pressões sociais por moradia.

É possível destacar como uma das principais modificações do rio, o desvio de seu curso após o bairro São José na década de 1940, onde a vazão do rio foi desviada para desaguar no rio Mandacaru, que é um afluente do rio Paraíba, proporcionando a urbanização do bairro do Bessa, pois reduziu o fluxo de águas na planície costeira desta região nos anos de 1980.

Por ser um rio totalmente inserido na malha urbana da cidade de João Pessoa ${ }^{5}$, a quantidade de tipos de $5 \mathrm{O}$ rio Jaguaribe, como os outros 2 rios dessetrabalho são considerados intraurbanos. 
impactos a que este está submetido é muito grande, devido a diversidade das características urbanísticas de cada trecho inserido na bacia hidrográfica do rio Jaguaribe, que atualmente, teve muitas de suas feições ou perfis hidrográficos alterados pelo avanço da expansão urbana (Figura 5).

Figura 5 - Mapa de Localização do rio Jaguaribe.

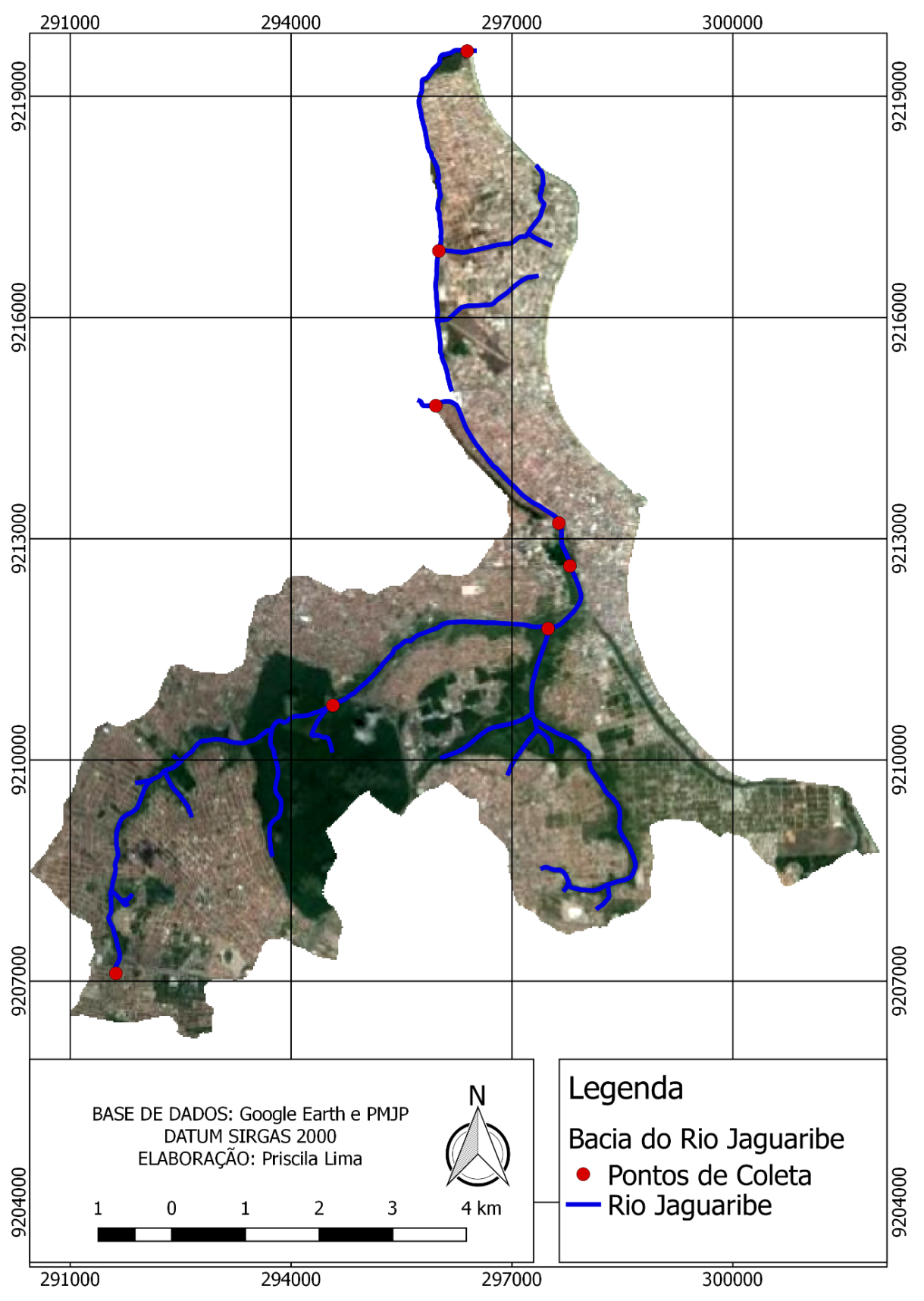

Fonte: Elaboração - Priscila Lima, 2016.

Assim, o monitoramento da qualidade da água realizado em laboratório, reforça a prerrogativa de que as modificações urbanísticas a que a bacia hidrográfica do rio Jaguaribe sofreu ao longo dos anos, implicou em uma forte degradação ambiental proveniente das demandas sociais relacionadas a melhorias dos indicadores socioeconômicos locais (Quadro 5). 
Quadro 5 - Desempenho dos Indicadores de Sustentabilidade do rio Jaguaribe.

\begin{tabular}{|c|c|c|c|}
\hline DIMENSÕES & INDICADORES & NOTA & COR \\
\hline \multirow{4}{*}{ Ambiental } & $\begin{array}{l}\text { Domicílios particulares permanentes - abastecimento de água - Rede } \\
\text { geral }\end{array}$ & 95 & \\
\hline & Parâmetros de Qualidade da água & 15 & \\
\hline & $\begin{array}{l}\text { Domicílios particulares permanentes - tipo de saneamento - total - } \\
\text { adequado - Acesso ao esgotamento sanitário (Taxa) }\end{array}$ & 72 & \\
\hline & $\begin{array}{l}\text { Domicílios particulares permanentes } \\
\text { - Destino do lixo - Coletado (taxa) }\end{array}$ & 99 & \\
\hline \multirow{4}{*}{ Institucional } & Implementação e Monitoramento do Desenvolvimento Sustentável & 35 & \\
\hline & Monitoramento de Áreas de Preservação Permanente & 22 & \\
\hline & Preparo e Resposta a Desastres Naturais & 7 & \\
\hline & Planejamento e Acesso a Informações & 7 & \\
\hline \multirow{5}{*}{ Social } & Notificações por doenças de transmissão e veiculação hídrica & 46 & \\
\hline & Adensamento Populacional & 100 & \\
\hline & Taxa de domicílios com um ou mais banheiros & 99 & \\
\hline & Domicílios com energia elétrica fornecida por distribuidora & 99 & \\
\hline & Taxa de Alfabetização per capta & 88 & \\
\hline \multirow{7}{*}{ Econômica } & $\begin{array}{l}\text { Classes de rendimento nominal mensal domiciliar per capita até } 1 / 4 \text { de } \\
\text { salário mínimo (taxa). }\end{array}$ & 92 & \\
\hline & $\begin{array}{l}\text { Classes de rendimento nominal mensal domiciliar per capita entre } 1 / 4 \mathrm{e} \\
\qquad 1 / 2 \text { salário mínimo (taxa). }\end{array}$ & 85 & \\
\hline & $\begin{array}{l}\text { Classes de rendimento nominal mensal domiciliar per capita entre } 1 / 2 \mathrm{e} \\
\qquad 1 \text { salário mínimo (taxa). }\end{array}$ & 80 & \\
\hline & $\begin{array}{l}\text { Classes de rendimento nominal mensal domiciliar per capita entre } 1 \text { e } \\
\qquad 2 \text { salários mínimos (taxa). }\end{array}$ & 17 & \\
\hline & $\begin{array}{l}\text { Classes de rendimento nominal mensal domiciliar per capita entre } 2 \text { e } \\
\qquad 3 \text { salários mínimos (taxa). }\end{array}$ & 10 & \\
\hline & $\begin{array}{l}\text { Classes de rendimento nominal mensal domiciliar per capita entre } 3 \text { e } \\
\qquad 5 \text { salários mínimos (taxa). }\end{array}$ & 12 & \\
\hline & $\begin{array}{c}\text { Classes de rendimento nominal mensal domiciliar per capita }>5 \text { salá- } \\
\text { rios mínimos (taxa). }\end{array}$ & 18 & \\
\hline
\end{tabular}


Dentre todas as bacias hidrográficas estudadas, a do rio Jaguaribe é a de maior extensão territorial, mas de maneira generalizada, a tendência de desempenho de seus indicadores, segue as demais, com apenas algumas diferenças pontuais na performance das dimensões, devido a diversidade dos bairros que a compõem.

Uma das características mais marcantes na avalição de seus indicadores é que dentre as 3 bacias hidrográficas estudadas, a má distribuição de renda é mais evidente, pois é onde estão concentrados o maior número de pessoas com as maiores rendas e o menor número de pessoas com as rendas mais baixas. Mesmo assim, a faixa de rendimento médio, onde deveria se concentrar a população, para que fosse considerada uma condição equitativa de sustentabilidade econômica, apresenta um desempenho de 17 pontos.

O pior indicador da dimensão ambiental é o de qualidade da água, já evidenciado pelo monitoramento realizado durante um ano de campanhas de coleta. Os impactos identificados para que este indicador tenha uma baixa performance é o lançamento de agentes poluentes proveniente de ligações clandestinas de esgoto doméstico pela população e até mesmo o lançamento indevido de esgoto bruto pela CAGEPA, quando as estações elevatórias não suportam a vazão de esgoto que deveria ser recalcado para a estação de tratamento de efluentes.

Em todas as estações de monitoramento da qualidade da água em todo o curso do rio (nascente até sua foz) praticamente todos os parâmetros analisados estão foram das especificações do CONAMA 357. Inclusive quando parte do curso do rio passa pela reserva florestal do Jardim botânico Benjamin Maranhão.

Os impactos no curso do rio são identificados pelo assoreamento, eutrofização, construção as margens do rio e o lançamento clandestino de esgoto doméstico. As pressões ambientais a que o rio está submetido são inúmeras e refletem o avanço desordenado da urbanização e a percepção da população em relação aos rios urbanos.

Mesmo com uma cobertura de saneamento acima da média em relação as demais bacias hidrográficas analisadas, com desempenho na faixa de 72 pontos, o rio sofre com pressões externas aos limites da bacia, sendo potencializados no curso do rio. O trecho mais crítico é na altura do bairro São José, onde, independente das condições em que o rio se encontra antes de chegar nesse local, a urbanização ocupou suas margens indiscriminadamente pressionando ainda mais a qualidade das funções ecossistêmicas do rio.

Pelo que é mostrado pelo indicador da dimensão social de domicílios com banheiro (99 pontos) e pelo indicador ambiental de domicílios ligados a rede geral de esgoto (72 pontos), deveriam indicar reflexos positivos no indicador ambiental de qualidade da água, contudo, existem externalidades ao território da bacia hidrográfica do Jaguaribe que comprometem o desempenho deste indicador.

Os demais indicadores ambientais apresentam um desempenho positivo segundo os dados do IBGE e apresentados no Quadro 5.

Os indicadores da dimensão Institucional já foram discutidos anteriormente, pois devido sua natureza de indiciadores universais e suas ações focam não somente o território de uma bacia hidrográfica específica, mas para todo o município de João Pessoa, a avaliação é ampliada e replicada para todos os locais estudados. Assim, o desempenho dessa dimensão é muito baixo devido a impossibilidade de evidenciar a existência de estruturas operacionais que viabilizem a execução das diretrizes dos indicadores, ou seja, não há evidência, segundo critérios legais ou institucionais da operacionalização desses indicadores.

Um exemplo da ausência de ações governamentais eficientes, que fazem parte da avaliação dos indicadores da dimensão institucional são as condições evidenciadas no bairro São José, onde a população tem seus domicílios 
a margem do rio, submetida a inúmeros riscos ambientais e de doenças de transmissão hídrica.

$\mathrm{Na}$ dimensão Social, todos os indicadores apresentam um bom desempenho segundo os dados do IBGE, contudo é importante ressaltar que quanto melhor o desempenho em uma dimensão, maior pode ser a pressão no indicador de outra dimensão.

O indicador de notificações de doenças de transmissão e veiculação hídrica identificado na bacia do rio Jaguaribe teve o pior desempenho, pois houve inúmeras notificações de ocorrências relativas a esse tipo de doença, contudo, vale ressaltar a possibilidade do número de casos ser maior do que os registrados nas estatísticas, mesmo assim, a incidências desses casos é um fator considerado pelo poder público para a definição de políticas públicas de saúde ambiental (Quadro 5 e Figura 5).

\section{Discussão}

Costa (2006) afirma a importância da valoração ambiental do rio como elemento mutante da paisagem urbana, é mais do que apenas um elemento da dinâmica de drenagem e saneamento, pois a bacia hidrográfica é a unidade de gestão espacial paisagística indissociável ao ambiente fluvial urbano.

A problemática dos rios urbanos não pode ser desvinculada da dinâmica da produção do espaço, pois ao impactar negativamente na qualidade social, cultural e ambiental das cidades, distribuindo os riscos, de maneira desigual a sociedade como um todo, sendo essa reflexão observada por Coelho (2001), onde a ecologia política é responsável por visualizar os impactos biofísicos inerentes aos impactos sociais.

Essa afirmação é completada por Gorski (2010), ao se apresentar como fator de potencialização dos impactos urbanos sobre os rios, a poluição difusa por vias indiretas, advinda das redes de drenagem urbana ${ }^{6}$, remoção de vegetação marginal ou matas ciliares, ou por vias diretas, como uso e ocupação do solo ao longo dos cursos dos rios, lançamento indevido (qualitativamente ou quantitativamente) de efluentes domésticos, industriais ou agrícolas.

Os rios das três bacias hidrográficas que compõem o estudo são enquadrados de acordo com a SUDEMA, como rios de Classe III do CONAMA 357, apresentando suas vertentes com o padrão predominante dos baixos planaltos costeiros, convexas, bem dessecadas, com suco principal aprofundado pelo escoamento superficial e pela ação humana O Baixo Planalto é cortado por vários vales fluviais, configurando "vales de fundo chato", cujos rios perenes correm paralelos entre si, separando a superfície em blocos às vezes extensos, pouco dessecados como os do litoral norte, às vezes bem mais erodidos, semi-colinosos, como os do litoral sul, demonstrando a interferência cada vez maior, daí para o sul, dos climas úmidos e dos processos erosivos do escoamento pluvial (PMCR MA, 2010).

Nos últimos 50 anos as cidades têm evoluído na concepção do planejamento urbano, contudo, na capital do Estado da Paraíba, João Pessoa, o gerenciamento do crescimento da cidade reflete uma dinâmica histórica diferenciada das demais capitais do Brasil, na construção do espaço urbano.

Historicamente, João Pessoa desenvolveu seus aspectos urbanos a partir de inúmeras intervenções de cunho político e desenvolvimentista desde o período colonial, seguindo o curso inverso das outras cidades do Nordeste, como Recife e Natal, onde, ao invés de ampliar sua malha urbana do litoral para o centro, seguiu do centro para o litoral, segundo, Moura Filha (2004). Essa característica foi suficiente para refletir até hoje nos 6 Segundo Gorski, (2010), a rede de drenagem urbana é um dos maiores difusores da poluição, bem como um dos geradores de calamidade pública nas áreas urbanizadas na estação das chuvas. 
métodos de planejamento urbano da capital paraibana.

E para fazer essa reflexão histórica do desenvolvimento da cidade, é importante destacar os conceitos de produção do espaço geográfico urbano e de como essa produção interferiu no território da capital paraibana.

Segundo Correa (1989), a análise em relação a produção do espaço urbano é estabelecida a partir da relação entre os agentes sociais e a escala. Onde o primeiro, é o fator de concreto de construção do ambiente e o segundo é a dimensão espacial na qual a ação humana é efetivamente realizada.

Assim, é partir deste contexto que as estratégias determinadas pelo poder público são apresentadas como prioridades na condição da reprodução e crescimento da cidade e homologadas por diretrizes legais, onde em João Pessoa, de acordo com Coutinho (2004), durante a década de 1970, quando surgiu toda a base da atual legislação urbanística.

João Pessoa já contava com inúmeros planos urbanístico datados da década de 1920, elaborados pelo escritório de Saturnino de Brito e nos anos de 1930 a 1937, período marcado pelo Estado Novo, foi contratado o arquiteto urbanista Nestor Figueiredo, pelo interventor Gratuliano de Brito (Trajano, 1999), como forma a subsidiar a elaboração do primeiro Plano Diretor Municipal, seguindo o exemplo do Plano de Avenidas de Prestes Maia em São Paulo, contudo, esse plano não foi efetivado, sendo um desses projetos o desvio do curso do rio Jaguaribe.

Em relação ao projeto de alteração do curso do rio Jaguaribe, houveram mais do que modificações físicas no ambiente, pois segundo Lemos (2005), essa foi uma obra necessária, na tentativa de diminuir os focos de mosquitos de febre amarela a montante, em Manaíra, fato atribuído às enchentes frequentes do rio ainda segundo Nóbrega (2002), a obra foi realizada na mesma época da implantação do sistema de esgotamento sanitário do centro da cidade de João Pessoa, da drenagem da lagoa do Parque Sólon de Lucena.

Por este motivo, acredita-se que o projeto, atribuído a Saturnino de Brito, visava também aumentar a vazão do rio Paraíba que passaria a receber os esgotos domésticos a montante do trecho desviado, na CamboaTambiá Grande. Assim, essa medida paliativa serviria para depurar as águas do Rio Paraíba, bem como para sanear o bairro de Manaíra que se apresentava insalubre com frequentes alagamentos.

Coutinho (2004) ainda destaca, que mesmo com diversos avanços tecnológicos e a crescente desigualdade social, presente em todo o país, o planejamento urbano municipal (referindo-se a João Pessoa), seja ele no período colonial ou da república, os gestores públicos atuam de maneira desarticulada as principais questões da evolução urbana. Como o autor destaca a questão de mobilidade, ou como Advíncula (2009), destaca a questão das redes de águas e esgoto, no período compreendido de 1910 a 1926, ou Farias (1997) que destaca os aspectos de urbanização e modernidade na construção do espaço urbano de João Pessoa dos anos 20 aos anos 70.

Sendo necessário salientar que as diretrizes urbanas seguem o perfil administrativo de cada gestor municipal.

Vale destacar o que foi ressaltado por Coutinho (2004), que a elaboração e reforma das diretrizes urbanas em João Pessoa não ocorreram em uma única fase, pois para que estas fossem implementadas, foram necessárias a consolidação das infraestruturas básicas como pré-requisito para a expansão urbana (saneamento, drenagem, transporte), que inexistiam até o início do século XX.

Então a partir da década de 1920, o principal fato que consolidaria o processo de modificação da paisagem urbana em João Pessoa, segundo Leitão (1998) foram a construção da Ferrovia Tambaú e a Orla Marítima, pois ligariam o centro da cidade ao Oceano Atlântico, e partir deste marco, os gestores municipais foram se alternando, contudo, mantendo a política do crescimento urbano, mas ainda bastante focado nas zonas centrais 
que originaram a cidade e que hoje é o centro comercial e urbano de João Pessoa.

Porém, todas essas intervenções na zona central da cidade, tiveram seus custos, não somente financeiros, bem como ambientais.

Em sua tese de doutorado, pela Universidade Federal da Bahia, Araújo (2012) detalha minuciosamente diversas nascentes localizadas na região central da cidade e com o passar do tempo e do avanço da urbanização, essas ressurgências de águas naturais, importante recurso para população, foram sendo suprimidas ou contaminadas, e restando poucas delas nos dias atuais, mais sem uso pela população.

O estudo ainda reforça os impactos ambientais no recorte temporal dessas intervenções urbanas em relação as grandes alterações da fisiografia da região (relevo, redes de drenagem e qualidade da água), corroborando com a dissertação de mestrado intitulada: "Entre miasmas e micróbios: a instalação de redes de água e esgoto na cidade da Parahyba do Norte (PB) e outras medidas de salubridade - 1910/1926”, de Chyara Charlotte Bezerra Advíncula, em 2009, pelo programa de pós graduação em história da UFPE.

Quando no mesmo período do desenvolvimento urbano de João Pessoa, em direção ao oceano, as nascentes dos rios foram extintas devido à necessidade de outros aparelhos públicos da vida urbana, como calçamento, redes de escoamento, abastecimento de água, transporte e tratamento de efluentes domésticos, etc.

Ou seja, na medida que as interações e necessidades da população urbana fica mais complexa e não havendo base reguladora para disciplinar o uso do espaço urbano, com foi caso até o final do século XX, os recursos naturais, são de certa forma "sacrificados" em nome do progresso.

\section{Conclusão}

A discussão que precisa ser feita a partir dos dados coletados pertinente a pesquisa das bacias hidrográficas estudadas e de maneira geral aos demais rios de João Pessoa é de ordem política e institucional. Existe a necessidade de repensar a unidade territorial para o planejamento urbano. Atualmente, a bacia hidrográfica ou os limites territoriais administrativos (limites municipais) são as unidades de planejamento legalmente aceitas. Contudo, a dinâmica urbana não se limita aos limites topográficos ou das jurisdições do poder público estadual ou municipal e ainda partindo do pressuposto que as externalidades impactam e tem seus efeitos negativos ou positivos que vão além dessas fronteiras em qualquer escala (global, regional ou local).

É possível mensurar nas bacias hidrográficas o desempenho de seus indicadores nas dimensões do desenvolvimento sustentável pelo método do painel da sustentabilidade. Contudo, o planejamento urbano focado em um índice de maneira individual e fragmentado é pouco produtivo, pois não considera a integração e a conexão entre os territórios urbanos de uma cidade, direcionando uma única diretriz para os diversos locais, sem considerar suas diferenças.

Os quadros que apresentam os resultados analíticos do monitoramento da qualidade da água e de algumas variáveis microclimáticas são a principal evidência de que os recursos hídricos urbanos sofrem com a baixa performance dos indicadores das demais dimensões da sustentabilidade, proposto pelo método do Dashboard Sustainability. Na verdade, os parâmetros de qualidade da água, diagnosticados na pesquisa, é o reflexo dos efeitos deletérios causados pela priorização de ações que não promovem o equilíbrio dinâmico entre os fatores de crescimento urbano e o ambiente natural que precisa ser preservado.

Outro fator que reflete na qualidade ambiental do meio urbano, sobretudo nas bacias hidrográficas 
pesquisadas é a fragmentação da sustentabilidade pela ótica do desenvolvimento da cidade, segregando as diretrizes ambientais, econômicas e sociais, e não visualizando todas de maneira integrada. A desarticulação entre os órgãos governamentais é evidente ao se tratar da gestão de recursos hídricos de maneira integrada.

Um exemplo dessa desarticulação está representado na relação dos indicadores ambientais dos domicílios que estão ligados a rede geral de abastecimento de água. O desempenho desse indicador é excelente, pois em todas as bacias hidrográficas estudadas, a cobertura é de quase $100 \%$, mas a bacia hidrográfica que serve para abastecimento público é fora dos limites do município de João Pessoa, contudo, o percentual de domicílios ligados a rede de coleta, transporte e tratamento dos efluentes domésticos, não chega a $50 \%$, e os rios que recebem esse efluente tratado ou bruto, como foi evidenciado durante o trabalho de campo, estão totalmente inseridos na malha urbana.

Por exemplo, a bacia hidrográfica onde está localizada a ETE da CAGEPA de Mangabeira é a do rio Cuiá. Contudo, o esgoto tratado e lançado na calha do rio é gerado em outra bacia hidrográfica, transportado pela cidade através das Estações Elevatórias. Ou seja, indicadores sociais e ambientais (banheiros nos domicílios, rede de coleta de esgoto, lixo coletado) gerados em uma bacia hidrográfica, refletem nos indicadores ambientais e sociais de outra bacia hidrográfica (qualidade da água e taxa de notificações de doenças de transmissão e veiculação hídrica).

Desta forma, todos os indicadores escolhidos para compor o Índice de Sustentabilidade Final da Bacia Ambiental que integre as 3 bacias hidrográficas, estão interconectados, não por proximidades territoriais e sim pela relação dos indicadores das dimensões da sustentabilidade.

Os resultados encontrados focam de maneira direcionada uma forma de convergir os dados coletados em campo e de como as condições ambientais encontradas durante o período de monitoramento refletem os impactos e as pressões provenientes das ações antrópicas urbanas.

\section{REFERÊNCIAS}

Advíncula CCB. 2009. Entre miasmas e micróbios: a instalação de redes de água e esgoto na cidade da Parahyba do Norte (PB) e outras medidas de salubridade - 1910/1926. Dissertação de Mestrado Programa de Pós-graduação em Geociências, Centro de Filosofia e Ciências Humanas da UFPE. Recife.

Araújo ME. 2012. Água e Rocha na Definição do Sítio de Nossa Senhora das Neves, Atual Cidade João Pessoa - Paraíba. Tese de Doutorado - Programa de Pós-Graduação em Arquitetura e Urbanismo da Universidade Federal da Bahia.

Beltrame ÂV. 1994. Diagnóstico do meio físico de bacias hidrográficas. Modelo e Aplicação. Florianópolis: Editora UFSC, 152p.

Benetti LB. 2006. Avaliação do Índice de Desenvolvimento Sustentável através do Método do Painel de Sustentabilidade (IDS) do município de Lages/SC. Santa Catarina. Tese de Doutorado - Programa de Pós-graduação em Engenharia Ambiental da Universidade Federal de Santa Catarina.

BRASIL. Resolução CONAMA 357 de 17 de março de 2005. Brasília: promulgada em 5.10.1988. Disponível 
em: www.planalto.gov.br/ccivil 03/constituição/constituição.htm. Acesso em 05/11/2014.

Buarque SC. 2008. Construindo o desenvolvimento local sustentável - Metodologia de Planejamento, Editora Garamond. Rio de Janeiro, 145p.

Coelho MCN. 2006. Impactos ambientais em áreas urbanas: teorias, conceitos e métodos de pesquisa. In: Impactos ambientais urbanos no Brasil, Bertrand, Rio de Janeiro, Brasil, 196 p. De 87 - 104 p.

Correa RL. 19m89. A Rede Urbana, Ática. São Paulo, 125p.

Costa LMSA. (org.). 2006. Rios e paisagens urbanas em cidades brasileiras. Rio de janeiro:Editora Viana \& Mosley/Proub. 134p.

Coutinho MAF. 2004. Evolução Urbana e Qualidade de Vida: O caso da Avenida Epitácio Pessoa em João Pessoa Paraíba. Dissertação de Mestrado - Programa de Pós-Graduação em Desenvolvimento e Meio Ambiente - PRODEMAda Universidade Federal da Paraíba.

Farias AM. 1997. Urbanização e modernidade: A construção do especo urbano de João pessoa (dos anos 20 aos anos 70). Tese de Doutorado - Programa de Pós-Graduação em História da Universidade Federal de Pernambuco, Recife.

Gorski MCB. 2010. Rios e Cidades: Ruptura e Reconciliação, SENAC. São Paulo,242p.

IBGE - INSTITUTO BRASILEIRO DE GEOGRAFIA E ESTATÍSTICA. 2008. Indicadores de desenvolvimento sustentável. Rio de Janeiro.

JOÃO PESSOA. DECRETO N. ${ }^{\circ}$ 6.499, de 20 de março de 2009. Prefeitura Municipal de João Pessoa. CONSOLIDA A LEI COMPLEMENTAR N. 054, DE 23 DE DEZEMBRO DE 2008, ÀS DISPOSIÇÕES DA LEI COMPLEMENTAR N. ${ }^{\circ} 03$ DE 30 DE DEZEMBRO DE 1992. Disponível em: http://www. joaopessoa.pb.gov.br/portal/wp-content/uploads/2012/04/planodiretor2009.pdf. Acesso em 05/11/2014.

JOÃO PESSOA. PLANO DIRETOR DA CIDADE DE JOÃO PESSOA. LEI COMPLEMENTAR N. ${ }^{\circ}$ 3, DE 30 dezembro DE 1992 João Pessoa - PB, 1994. Disponível em: https://leismunicipais.com.br/planodiretor-joao-pessoa-pb. Acesso em 05/11/2014.

JOÃO PESSOA. PMJP. PREFEITURA MUNICIPAL DE JOÃO PESSOA/SEMAM/DIEP. PLANO MUNICIPAL DE CONSERVAÇÃO E RECUPERAÇÃO DA MATA ATLÂNTICA. DOSSIE MATA ATLÂNTICA. (PMCRMA) João Pessoa, novembro de 2010. Disponível em: https://www.sosma.org.br/wpcontent/uploads/2014/04/pmma_joao_pessoa.pdf. Acesso em 05/11/2014.

JOÃO PESSOA. PMJP. PREFEITURA MUNICIPAL DE JOÃO PESSOA. SECRETARIA DE SÁUDE DO MUNICIPIO. Departamento de Epidemiologia. Relatório de Agravos de doenças de transmissão e veiculação hídrica. João Pessoa, dezembro de 2010.

Leitão D. 1998. Ruas de Tambaú. João Pessoa. Governo do Estado da Paraíba, 265p. 
Lemos, NAB. 2005. Bacia hidrográfica urbanizada e degradação ambiental: o alto vale do rio Jaguaribe - João Pessoa (PB). Dissertação de Mestrado - Programa de Pós-Graduação em Desenvolvimento e Meio Ambiente (PRODEMA). Universidade Federal da Paraíba (UFPB). João Pessoa (PB).

Martinez ZTL.; Leiva FM. Avaliação comparativa de indicadores urbanos. Oficina Técnica de Planejamento Estratégico de Granada ñ Granada, Metrópole 21, 2003. Disponível em http://www.granada.org/obj.nsf/in/ CIHNBPA\$file/INDICADORES_URBANOS.pdf. Acesso em: 21 maio 2014.

MILLENNIUM ECOSYSTEM ASSESSMENT (MA), 2003. EcosystemandHumanWell-Being: a framework for assessment. Island Press, Washington, DC.

Moura Filha MBBL. 2004. De Filipéia à Paraíba. Uma cidade na estratégia de colonização do Brasil. Séculos XVI- XVIII. Tese de Doutorado - Faculdade de Letras, Universidade do Porto. Portugal

Nóbrega TMQ. 2002. A Problemática da Drenagem em Áreas Urbanas Planas: O caso da Planície Costeira da Cidade de João Pessoa. Dissertação de Mestrado - Programa de Pós-Graduação em Desenvolvimento e Meio Ambiente (PRODEMA). Universidade Federal da Paraíba (UFPB). João Pessoa (PB.

OECD. Indicators for theIntegrationof Environmental ConcernsintoTransport Policies, OECD EnvironmentMonograph, 1993.

Reis ALQ. 2010. Índice de Sustentabilidade Aplicado à Bacia do rio Cuiá - João Pessoa (PB). Dissertação de Mestrado - Programa Regional de Pós-Graduação em Desenvolvimento e Meio Ambiente PRODEMA da Universidade Federal da Paraíba, João Pessoa PB.

Reis, LB.; Fadigas EA.; CarvalhoCE. 2005. Energia, Recursos Naturais e a Prática do Desenvolvimento Sustentável, Editora Manole - Coleção Ambiental, São Paulo. 369p.

Sassi R.; Oliveira BR.; Araújo ME.; Moura GF.; Melo JA.; Melo GN. 1997. Estudo integrado das lagunas costeiras do Estado da Paraíba. João Pessoa. Relatório Técnico Final.

Silveira ALRC; Romero MAB. 2005. Indicadores de Sustentabilidade Urbana. IX Encontro Nacional da Associação de Pós-graduação e Pesquisa em Planejamento Urbano e Regional - ANPUR.

Trajano SF. 1999. Vanguarda e esquecimento: a arquitetura de Clodoaldo Gouveia. Monografia de conclusão de curso de Arquitetura e Urbanismo da Universidade Federal da Paraíba.

Van Bellen HM. 2006. Indicadores de Sustentabilidade: Uma Análise Comparativa, Editora FGV $2^{\circ}$ Edição. 129p.

Veiga JE.; Zatz L. 2008. Desenvolvimento Sustentável - Que bicho é esse? Autores Associados Ltda, São Paulo. 95p.

Xavier ALS. Desenvolvimento sustentável: um novo desafio para o século XXI. 2009. Disponível em http:// www.cte.com.br/site/artigos_ler.php/?id_artigo=1371. Acesso em: 20 maio. 2014. 